\title{
Magneto-Optic Properties of Ultrathin Nanocrystalline Ferrite Garnet Films in the 8K to 300K Temperature Interval
}

\author{
V. A. Kotov $\mathbb{D}^{1},{ }^{1}$ V. G. Shavrov, ${ }^{1}$ A. F. Popkov, ${ }^{2}$ M. Vasiliev, ${ }^{3}$ K. Alameh, ${ }^{3}$ M. Nur-E-Alam $\left(\mathbb{D},{ }^{3}\right.$ \\ L. N. Alyabyeva, ${ }^{4}$ D. E. Balabanov, ${ }^{4}$ V. I. Burkov, ${ }^{4}$ and M. K. Virchenko ${ }^{5}$ \\ ${ }^{1}$ Institute of Radio Engineering and Electronics, Russian Academy of Sciences, 11 Mohovaya St., Moscow 125009, Russia \\ ${ }^{2}$ National Research University of Electronic Technology-MIET, Bld. 1, Shokin Square, Zelenograd, Moscow 124498, Russia \\ ${ }^{3}$ Electron Science Research Institute, Edith Cowan University, 270 Joondalup Dr, Joondalup, WA 6027, Australia \\ ${ }^{4}$ Moscow Institute of Physics and Technology, 9 Institutski Per., Dolgoprudny 141700, Russia \\ ${ }^{5}$ NIIMV, 4/2 Georgievskiy Avenue, Zelenograd, Moscow 124460, Russia
}

Correspondence should be addressed to V. A. Kotov; kotov.slava@gmail.com and M. Nur-E-Alam; m.nur-e-alam@ecu.edu.au

Received 28 September 2017; Accepted 16 April 2018; Published 22 July 2018

Academic Editor: Anna D. Dobrzańska-Danikiewicz

Copyright (C) 2018 V. A. Kotov et al. This is an open access article distributed under the Creative Commons Attribution License, which permits unrestricted use, distribution, and reproduction in any medium, provided the original work is properly cited.

A study of the initial stages of crystallization in RF magnetron-sputtered ferrite garnet films is reported, in which a series of ultrathin $\mathrm{Bi}_{2} \mathrm{Dy}_{1} \mathrm{Fe}_{4} \mathrm{Ga}_{1} \mathrm{O}_{12}$ layers is fabricated and characterized. The spectral and temperature dependencies of magnetic circular dichroism (MCD) of these films are studied in the temperature range from $300 \mathrm{~K}$ down to $8 \mathrm{~K}$. Measured magnetooptical properties are reported in the spectral range between 300 and $600 \mathrm{~nm}$. In ultrathin garnets at temperatures below $160 \mathrm{~K}$, we found that between 360 and $520 \mathrm{~nm}$, the spectral MCD dependencies were typical of bismuth-substituted garnets with high levels of gallium dilution in the tetrahedral sublattice. The MCD signal strength measured at its $440 \mathrm{~nm}$ peak grows linearly with reducing temperature between $160 \mathrm{~K}$ and $8 \mathrm{~K}$. This observed temperature dependency of MCD differed dramatically from these measured in thicker $(3.7 \mathrm{~nm}$ ) nanocrystalline garnet films. The peak MCD signal at $440 \mathrm{~nm}$ in these $3.7 \mathrm{~nm}$-thick samples grows linearly from $215 \mathrm{~K}$ down to $100 \mathrm{~K}$, resembling the same dependency seen in $1.7 \mathrm{~nm}$ films. In thinnest layers of thickness $0.6 \mathrm{~nm}$, no MCD signals were observed at any temperature in the range between 8 and $300 \mathrm{~K}$.

\section{Introduction}

In recent years, there has been a significant research interest dedicated to the research fields related to the engineering and characterization of new-generation functional materials, in particular the ultrathin ferrite garnet films of thickness between several nanometers to several tens of nanometers. This is due primarily to the potential advantages of using yttrium-based iron garnets in one of the fast-developing areas of spintronics, which is related to the generation of spin-polarized currents in thin platinum films, assisted by the spin waves generated in yttrium iron garnet (YIG) films of nanoscale thickness $[1,2]$. Of particular importance is the fact that this material (YIG) possesses record-low losses in the ultra-high-frequency (UHF) spectral region, having a very small attenuation parameter $\alpha \approx 3 \times 10^{-5}$ and ferromagnetic resonance (FMR) linewidth of less than $0.5 \mathrm{Oe}$ (for monocrystalline YIG and LPEfabricated films) at $9 \mathrm{GHz}$. Thin films of ferromagnetic metals demonstrate attenuation parameters two orders of magnitude greater compared to those of YIG [3]. It has also been proposed that the use of ultrathin YIG films in spinvalve devices can lead to a significant reduction in the switching currents in these structures [4].

Thin films of bismuth-substituted ferrite garnets are undoubtedly of interest for the design of planar-integrated magneto-optic (MO) devices and also for designing waveguide-based MO modulators, nonreciprocal optical devices, and optical circulators. In planar optical waveguides made using films of bismuth-substituted ferrite garnets of 
high MO quality and narrow FMR linewidth, it is possible to achieve MO modulator as well as switching functionality at the working frequencies in the UHF range [5]. Nanocrystalline films of ferrite garnets with small attenuation in the UHF range and high MO quality factors have also been proposed for use in the engineering of new metamaterial types in the gigahertz and optical frequency ranges, as well as for the design of traditional UHF devices, such as bandpass filters utilizing magnetostatic waves [6].

Significant improvements in the MO quality of a range of magnetron-sputtered bismuth-substituted ferrite garnets compared to standard nanocrystalline garnet material have been achieved. Inside these nanocomposite bismuth-substituted ferrite garnet films, quasispherical nanocrystallites of garnets form inside a surrounding material matrix composed mainly of bismuth oxide. In samples of these nanocomposite ferrite garnets, the MO quality of the material (defined as $Q=2 \times\left|\Phi_{F}\right| / \alpha$ ) reaches $50^{\circ}$ at the wavelength of $633 \mathrm{~nm}$. Here, $\Phi_{F}$ is the specific Faraday rotation at the wavelength of interest, and $\alpha$ is the optical absorption coefficient at the same wavelength.

In another series of composite $\left(\mathrm{YIG}+\mathrm{Bi}_{2} \mathrm{O}_{3}\right)$ material synthesis experiments, amorphous-phase films of thickness near $500 \mathrm{~nm}$ were deposited, in which the excess volumetric fraction of bismuth oxide was near 20 vol.\%. After running the annealing crystallization process, a nanocomposite garnet-type material $\mathrm{Bi}_{0.5} \mathrm{Y}_{2.5} \mathrm{Fe}_{5} \mathrm{O}_{12}$ was obtained, in which the X-ray diffraction (XRD) characterization experiments revealed the presence of bismuth-substituted yttrium iron garnet crystallites of average size $36 \mathrm{~nm}$, and the crystal lattice parameter $a_{\mathrm{f}}(\perp)=12.450 \AA$. Also, a peak-to-peak FMR linewidth was found to be as low as $\Delta H_{\mathrm{pp}}=6.1 \mathrm{Oe}$ at $9.77 \mathrm{GHz}$ [7]. It is well-known that the substitution of one stoichiometric formula unit of $\mathrm{Bi}$ into YIG lattice leads to increasing the material's lattice parameter by $\Delta a=0.0829 \AA$ [8]. Based on these data, we can conclude that the lattice parameter $a_{\mathrm{f}}(\perp)=12.450 \AA$ corresponds, in undeformed nanocrystallites, to the composition $\mathrm{Bi}_{0.5} \mathrm{Y}_{2.5} \mathrm{Fe}_{5} \mathrm{O}_{12}$, according to the relationship $a_{\mathrm{f}}=12.376 \AA+0.5 \cdot 0.0829 \AA=12.42 \AA$, in which the value of $12.376 \AA$ is the lattice parameter of YIG, and 0.5 is the bismuth substitution coefficient in formula units.

Moving towards depositing ultrathin garnet films of thickness near $10 \mathrm{~nm}$ highlights the necessity of undertaking new studies of the fine structure inside the transitional layers existing between the substrate and film materials, since the presence of these layers can change dramatically the magnetic properties of nanoscale films compared to these found in bulk materials or thicker film layers.

It has also been observed that in garnet films grown by LPE, the transitional layers have in fact been composed of two sublayers. The first sublayer of thickness $1-5 \mathrm{~nm}$, which is known as the physical transition layer, represents a physical region of transition in between the substrate and film materials, with its thickness being determined primarily by the quality of substrate polishing $[9,10]$. Above this first sublayer of the substrate-to-film transition layer, there exists a technological (epitaxy-related) transition sublayer, the formation of which is due to the special features of the initial stage of the liquid-phase epitaxy process: the entry of substrate into the solution-melt without rotating the substrate during the first minute, the switch-on of the substrate rotation at 60-100 RPM, and the onset of thermodynamic equilibrium inside the solution-melt lead to the formation of a technological transitional layer of thickness between 5 and $300 \mathrm{~nm}$ depending on the value $\Delta T_{\mathrm{s}}$ of supercooling of the solution-melt. This boundary layer is located near the substrate-film interface (stationary boundary layer), through which the control of the steady-state diffusion of garnet-forming compounds from the bulk of melt-solution occurs towards the growth surface. The thickness of this technological transition layer can vary widely, from a few nanometers (for high growth temperatures in excess of $900^{\circ} \mathrm{C}$ and small melt supercooling of $\Delta T \approx 2-5^{\circ} \mathrm{C}$ ) to several hundred nanometers (for growth temperatures near $700^{\circ} \mathrm{C}$ and melt supercooling of $\Delta T \approx 100-150^{\circ} \mathrm{C}$ and above [10]). The measurements have shown that under the conditions of high growth temperature and low supercooling $\Delta T_{\mathrm{s}}$ of the solution-melt, the Curie temperature of a $5 \mathrm{~nm}$-thick epitaxial layer forming between the substrate and the main part of epitaxial layer did not differ from the Curie temperature of the main part of the epitaxial layer. At the same time, the measurements provided on $1.0 \mu \mathrm{m}$-thick epitaxial garnet layers of composition $\mathrm{Bi}_{0.45} \mathrm{Sm}_{0.20} \mathrm{Tm}_{2.35} \mathrm{Fe}_{4.30} \mathrm{Ga}_{0.70} \mathrm{O}_{12}$ demonstrated an initial part of the transitional layer of $100 \mathrm{~nm}$ thickness having a $T_{c}=225^{\circ} \mathrm{C}$, and in the technological transition layers of thickness $200 \mathrm{~nm}$, we observed a drop in $T_{\mathrm{c}}$ from $225^{\circ} \mathrm{C}$ to $215^{\circ} \mathrm{C}$ and a drop in the lattice parameter $a_{\mathrm{f}}(\perp)$ from $12.420 \AA$ to $12.411 \AA$ for epitaxial films grown at low temperature and at high value of supercooling $\Delta T_{\mathrm{s}}[10]$.

From the point of view of the practical applications of ultrathin garnet films, the RF magnetron sputtering process is most suitable for depositing amorphous-phase films onto GGG substrates, when followed by high-temperature annealing in air atmosphere at $550-650^{\circ} \mathrm{C}$ (depending on the level of bismuth substitution). The properties of transitional layers existing near the film-substrate interface represent a defining factor, which governs the annealing crystallization process, since the crystallization processes initialize within this transitional region. Bismuth-substituted ferrite garnets also remain the most perspective MO materials for applications in integrated photonics and magneto-plasmonics.

\section{Sample Fabrication Process}

A two-stage sample manufacturing methodology has been used for the preparation of ultrathin iron garnet films. During the first stage, amorphous-phase films of nominal stoichiometry $\mathrm{Bi}_{2} \mathrm{Dy}_{1} \mathrm{Fe}_{4} \mathrm{Ga}_{1} \mathrm{O}_{12}$ have been deposited onto GGG substrates using RF magnetron sputtering process. The film thicknesses were $0.6,1.7,3.7,10.3,50$, and $100 \mathrm{~nm}$, calculated based on the measured time durations of the deposition processes, using constant deposition rate approximation and previously obtained calibration data for the deposition rate versus the RF power density. Standard polished- (111) oriented GGG substrates of thickness $0.5 \mathrm{~mm}$ were used, heated to $250^{\circ} \mathrm{C}$ to improve the film adhesion and 


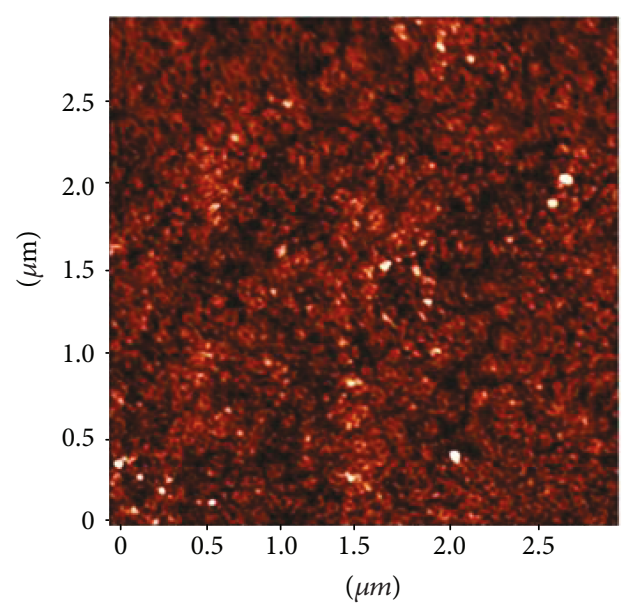

(a)

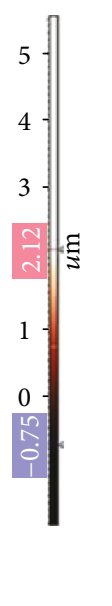

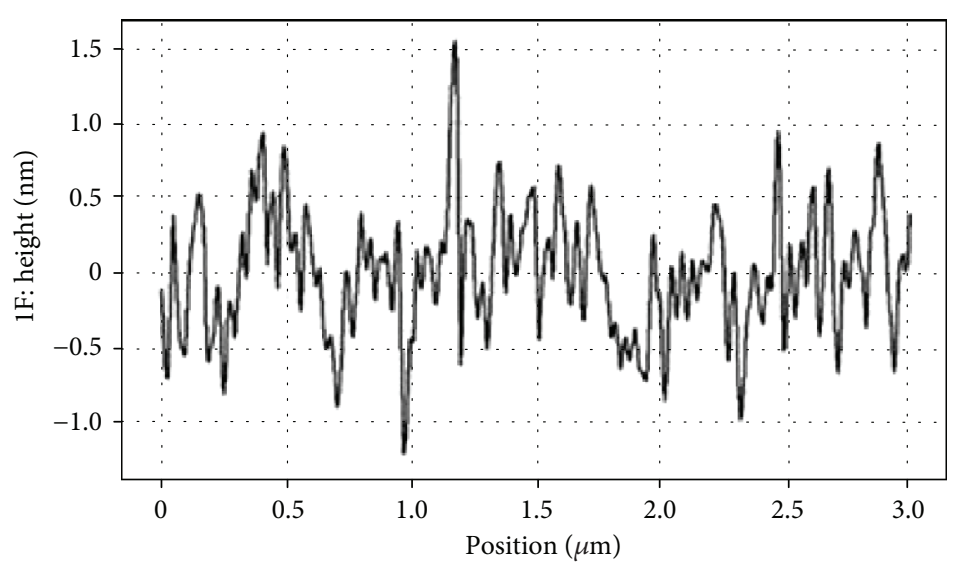

(b)

FIGURE 1: (a) GGG substrate surface relief image and (b) profile of GGG substrate-surface relief measured along a scan line across the area $(3 \mu \mathrm{m} \times 3 \mu \mathrm{m})$ shown in (a). A scanning step of $3.7 \mathrm{~nm}$ was used; the probe tip radius was less than $30 \mathrm{~nm}$.

density. The sputtering deposition processes were run in pure argon atmosphere at $1 \mathrm{mTorr}$, at RF power density of $4 \mathrm{~W} / \mathrm{cm}^{2}$ at the target surface, which led to a deposition rate close to $4 \mathrm{~nm} / \mathrm{min}$. The target-to-substrate distance was $18 \mathrm{~cm}$, and substrate rotation rate was 30 revolutions per minute.

The X-ray diffractometry (XRD) measurements have revealed that all films were amorphous in the phase following the deposition process. We also tested all samples for the presence of any magneto-optic activity using Faraday effect and magnetic circular dichroism measurements in the spectral region between 300 and $800 \mathrm{~nm}$. No signs of magnetooptic activity were detected in any of the amorphous film samples. During the second stage of the sample manufacture process, high-temperature annealing crystallization processes were run in air atmosphere in an electric oven for $1 \mathrm{~h}$, at temperatures ranging between 550 and $650^{\circ} \mathrm{C}$. XRD characterization experiments conducted with annealed film samples of thickness $50 \mathrm{~nm}$ and $100 \mathrm{~nm}$ have revealed the presence of garnet nanocrystallites of average dimensions near $40 \mathrm{~nm}$.

\section{Microstructural Investigation of Ultrathin Iron Garnet Films}

3.1. Surface Topography Studies. Figure 1 shows an AFM image revealing the surface relief of the GGG substrate (Figure 1(a)) and the GGG substrate surface relief profile measured along a linear path across the scan of Figure 1(b). When fabricating the ultrathin ferrite garnet films of nominal composition $\mathrm{Bi}_{2} \mathrm{Dy}_{1} \mathrm{Fe}_{4} \mathrm{Ga}_{1} \mathrm{O}_{12}$, we used the substrates with identical polishing quality applicable to both substrate sides, and the data of Figure 1 shows the back side of a substrate having a $1.7 \mathrm{~nm}$-thick film deposited onto its front side. The following scan parameters were used: semicontact mode of scanning, scan area of size $3 \mu \mathrm{m} \times 3 \mu \mathrm{m}, 750$ pixels $\times 750$ pixels (scan step of $4 \mathrm{~nm}$ ), and using a HA-FM-Pt series cantilever of less than $30 \mathrm{~nm}$ nominal tip radius.

An analysis of Figure 1(b) data at high magnification allows obtaining a zoom-in profile of the GGG surface relief, over a scanning interval from $0.9 \mu \mathrm{m}$ to $1.3 \mu \mathrm{m}$. The obtained data reveals that the substrate surface roughness was rather small and that the surface relief could be characterized by roughness features on a scale near $1 \mathrm{~nm}$. Along a $3 \mu \mathrm{m}$-long scan line, we could observe a single $1.6 \mathrm{~nm}$-high columnar feature and a single pit-like feature of depth $1.2 \mathrm{~nm}$ (scan line started from the zero height and probe starting position, as shown in Figure 1(b)).

Figure 2(a) shows the surface relief images of an ultrathin $(1.7 \mathrm{~nm}$ thick) garnet film of nominal composition $\mathrm{Bi}_{2} \mathrm{Dy}_{1} \mathrm{Fe}_{4} \mathrm{Ga}_{1} \mathrm{O}_{12}$, fabricated on the same substrate using RF magnetron sputtering, followed by annealing crystallization process run at $650^{\circ} \mathrm{C}$. Figure 2 (a) reveals a film surface roughness of around $2 \mathrm{~nm}$ and the presence of isolated features of height significantly greater than RMS roughness. Figure 2(b) shows the surface structure details of the same film, obtained from a part of Figure 2(a) scan in the region without any large roughness outliers present. The analysis of data shown in Figure 2(b) reveals, in general, that the film's surface relief is rather similar to that of the GGG substrate. However, a large number of nanocrystallites of height dimensions up to $5 \mathrm{~nm}$ were seen, together with a limited number of even larger nanocrystallites. Figure 2(c) shows the surface relief line scan of this $1.7 \mathrm{~nm}$-thick ferrite garnet film, where neither the large nanocrystallites nor the obvious surface contaminants were present within the scanned path.

The analysis of Figure 2(d) shows a somewhat smaller surface roughness in this ferrite garnet film compared to GGG substrate. The data shows that surface relief is represented by small-height (near $0.2 \mathrm{~nm}$ ) typical roughness features, with base diameter of these features being near $30-50 \mathrm{~nm}$. The height-to-diameter ratio seen in these surface features is near 0.01-0.02, that is, the deposition of the $1.7 \mathrm{~nm}$-thick film did not affect significantly the initial roughness of the GGG substrate surface. We can also note a pit-like structure between 75 and $175 \mathrm{~nm}$ of the scan-line coordinates in Figure 2(d). It is possible that the bottom of this feature contained an amorphized surface, or a contaminated surface part, which prohibited the crystallization of the garnet layer. 


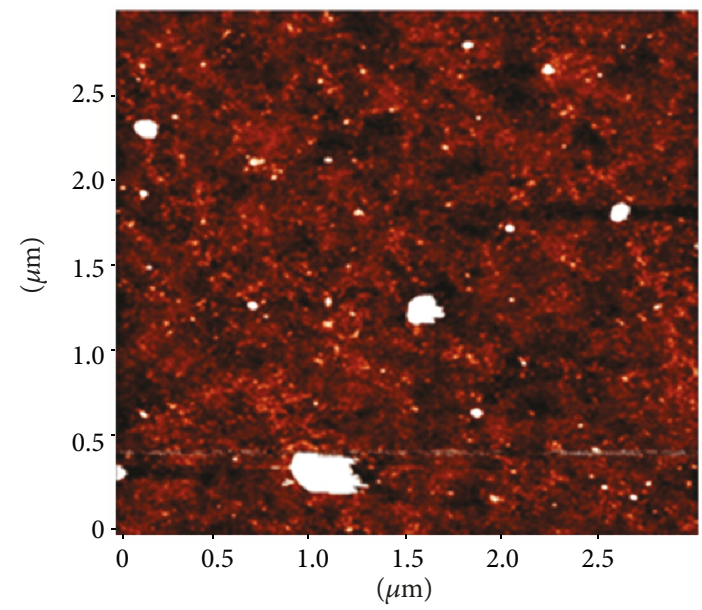

(a)

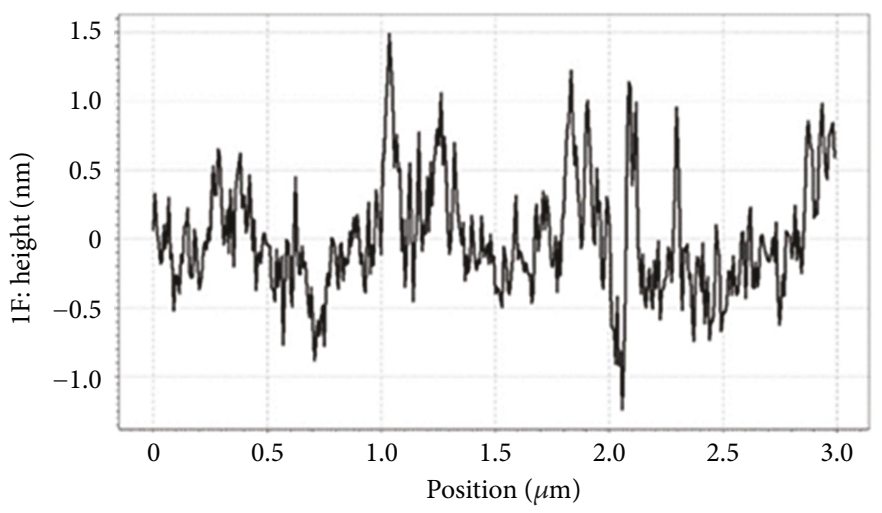

(c)

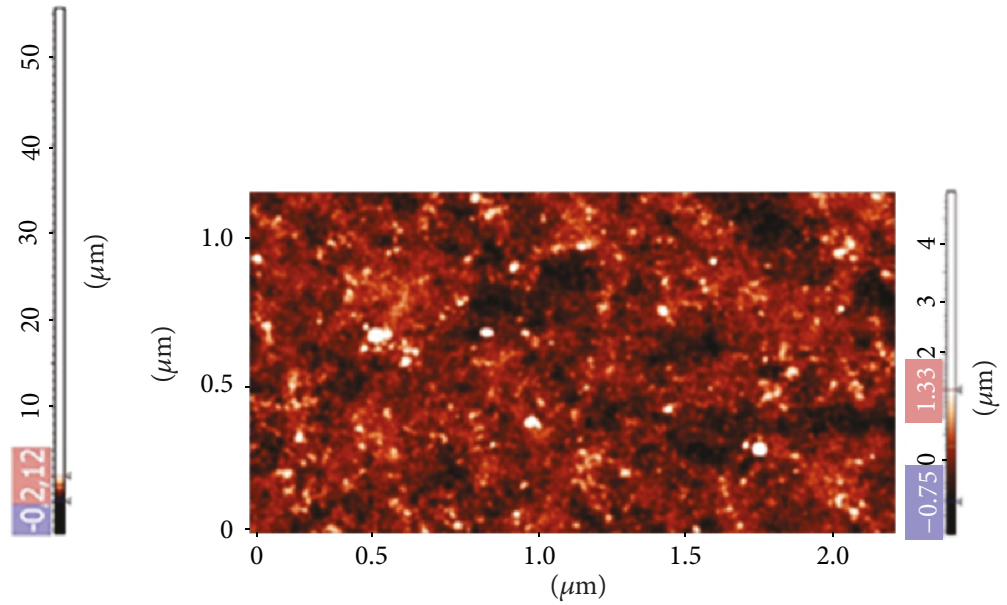

(b)

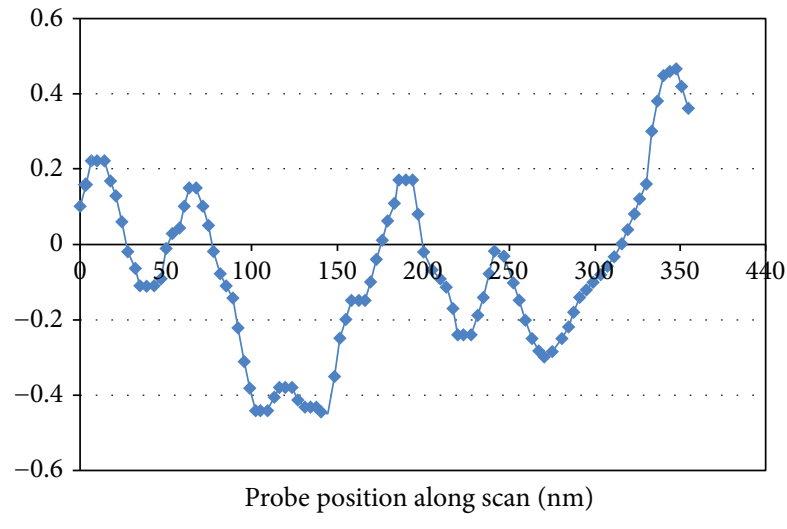

(d)

Figure 2: (a) AFM surface relief scan of an annealed ultrathin ferrite garnet film of nominal composition $\mathrm{Bi}_{2} \mathrm{Dy}_{1} \mathrm{Fe}_{4} \mathrm{Ga}_{1} \mathrm{O}_{12}$ and $1.7 \mathrm{~nm}$ thickness, deposited onto a GGG substrate. (b) Partial surface scan data from a flatter part of scan shown in (a). The larger nanocrystallites' height reaches $5 \mathrm{~nm}$. (c) Surface relief profile measured along a scanned line in a garnet film of nominal composition $\mathrm{Bi}_{2} \mathrm{Dy}_{1} \mathrm{Fe}_{4} \mathrm{Ga}_{1} \mathrm{O}_{12}$ and $1.7 \mathrm{~nm}$ thickness and (d) starting $400 \mathrm{~nm}$-long part of the line scan profile shown in (c).

Of special interest is the nature of larger nanocrystallite features of heights exceeding the nominal film thickness, which can be observed in Figure 2. It is possible that columnar growth morphology was present within some larger nanocrystallite islands which could have appeared due to adatoms merging within the growing ultrathin film. Details of the chemical composition and structure of these growth features within ultrathin garnet films remain to be investigated.

\subsection{X-Ray Diffraction Datasets of Thin Garnet Films of} Nominal Composition $\mathrm{Bi}_{2} \mathrm{D} \mathrm{y}_{1} \mathrm{Fe}_{4} \mathrm{Ga}_{1} \mathrm{O}_{12}$. During the studies of ferrite garnet films of different composition types deposited onto substrates heated to $300^{\circ} \mathrm{C}$, we clearly observed the $\mathrm{X}$-ray diffraction peaks related to the presence of magnetite $\left(\mathrm{Fe}_{3} \mathrm{O}_{4}\right)$. Figure 3 shows XRD datasets for nanocrystalline films of nominal composition $\mathrm{Bi}_{2} \mathrm{Dy}_{1} \mathrm{Fe}_{4} \mathrm{Ga}_{1} \mathrm{O}_{12}$ and for several nanocomposite-type films containing up to the estimated 49 vol.\% of excess cosputtered bismuth oxide. The crystalline microstructures of the annealed garnet-type thin films were determined by using a detector scan technique (at the near-grazing incidence source angle) using $\mathrm{CuK} \alpha_{1}$ radiation and covering the $2 \theta$ diffracted-beam angle range between $10^{\circ}$ and $80^{\circ}$. A software-assisted peak listing option was used to determine the precise angular positions of the $\mathrm{X}$-ray diffraction peaks and also to find the full-width halfmaximum (FWHM) values for each peak. From these experimental data, we were able to calculate the lattice parameter and the average crystallite size of these garnet thin film materials. It is reasonable to conclude that magnetite nanocrystallites formed already during the sputtering deposition process; this can be confirmed by the presence of $\mathrm{Fe}_{3} \mathrm{O}_{4}$-related peaks in the XRD signal shown in the bottom trace of Figure 3, which were measured in an amorphous (as-deposited) film on a glass substrate.

At first glance, the presence of $\mathrm{Fe}_{3} \mathrm{O}_{4}$ diffraction peaks in an amorphous-phase as-deposited sample is difficult to understand. However, the formation of magnetite nanocrystallites must have happened during the sputtering deposition process, since the substrate temperature $\left(250^{\circ} \mathrm{C}\right)$ was sufficiently high for $\mathrm{Fe}_{3} \mathrm{O}_{4}$ crystallization [11].

It is also possible to assume that during the annealing crystallization process at $650^{\circ} \mathrm{C}$, a partial loss of bismuth 

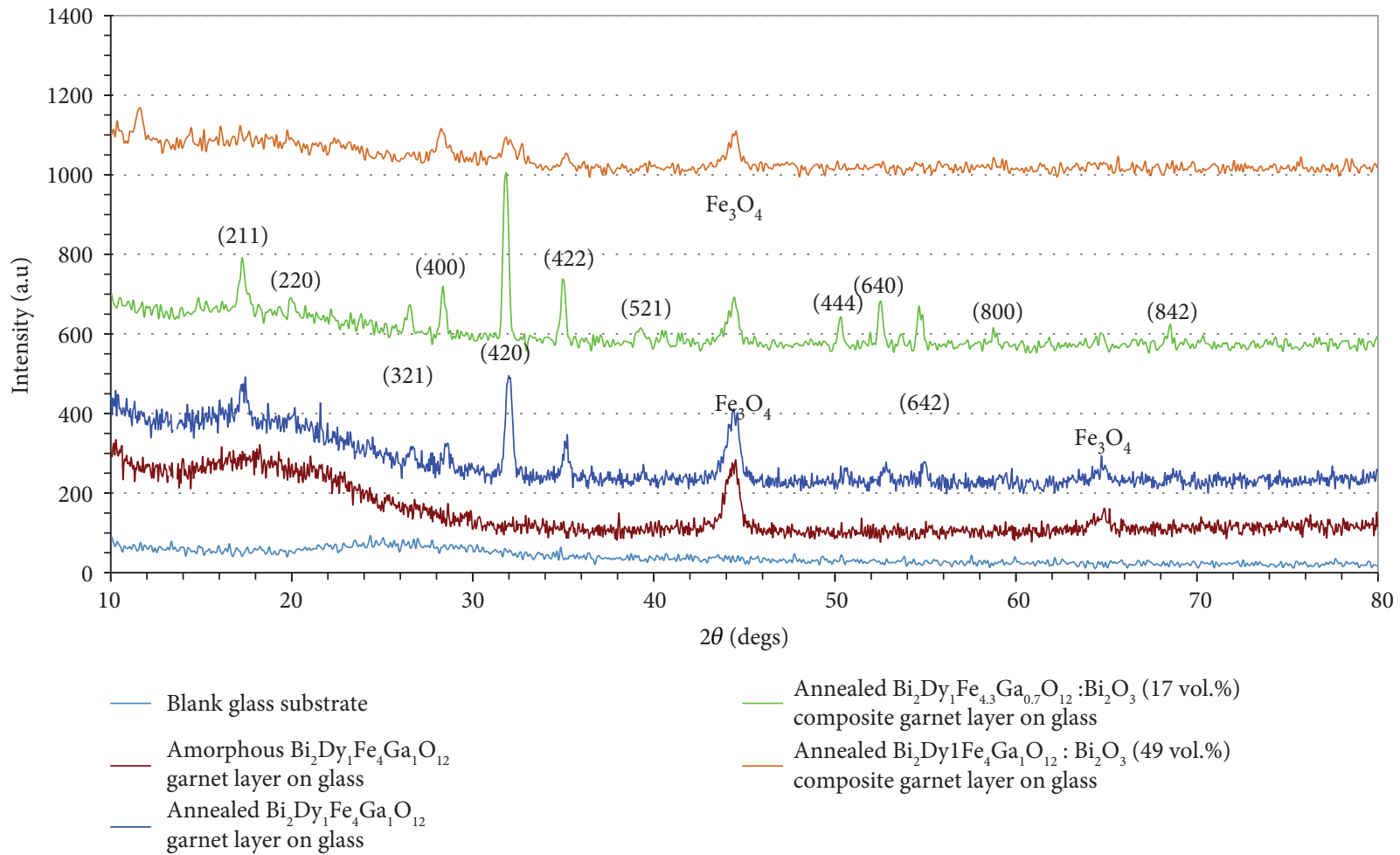

Annealed $\mathrm{Bi}_{2} \mathrm{Dy}_{1} \mathrm{Fe}_{4.3} \mathrm{Ga}_{0.7} \mathrm{O}_{12}: \mathrm{Bi}_{2} \mathrm{O}_{3}$ (17 vol.\%) composite garnet layer on glass Annealed $\mathrm{Bi}_{2}$ Dy1Fe $\mathrm{Ga}_{1} \mathrm{O}_{12}: \mathrm{Bi}_{2} \mathrm{O}_{3}$ (49 vol.\%) composite garnet layer on glass

FIgURE 3: XRD datasets obtained from nanocrystalline thin garnet films of nominal composition $\mathrm{Bi}_{2} \mathrm{Dy}_{1} \mathrm{Fe}_{4} \mathrm{Ga}_{1} \mathrm{O}_{12}$ and several nanocomposite-type films containing up to 49 vol.\% of excess cosputtered bismuth oxide. All films showed diffraction peaks characteristic of $\mathrm{Fe}_{3} \mathrm{O}_{4}$ nanocrystallites.

content occurred. This, in turn, results in the formation of nanocrystallites of the various oxides of iron, for example, $\mathrm{Fe}_{3} \mathrm{O}_{4}$ or $\mathrm{Fe}_{2} \mathrm{O}_{3}$. It is logical to expect that during the annealing crystallization, when the temperature is rising, starting from $250^{\circ} \mathrm{C}$, the formation of $\mathrm{Fe}_{3} \mathrm{O}_{4}$ nanocrystallites starts. According to the data of Figure 3, the crystallization of the garnet phase in thick (near $450 \mathrm{~nm}$ thickness) amorphous films of $\mathrm{Bi}_{2} \mathrm{Dy}_{1} \mathrm{Fe}_{4} \mathrm{Ga}_{1} \mathrm{O}_{12}$ is achieved across the film's bulk at $620^{\circ} \mathrm{C}$.

Earlier, when studying the ferrite garnet films of $\mathrm{Bi}_{2} \mathrm{Dy}_{1} \mathrm{Fe}_{4} \mathrm{Ga}_{1} \mathrm{O}_{12}$ of thickness near $300 \mathrm{~nm}$, we found that the film was composed of nanocrystallites of characteristic size between 20 and $40 \mathrm{~nm}$, with the average size being $36 \mathrm{~nm}$. Figure 4 shows the nanocrystalline structure of these garnet films. The imaging data were obtained using transmission electron microscopy (TEM). A focused ion beam (FIB) microscope (FEI XP200, FEI Company, Hillsboro, OR 97124, USA) was used to prepare the samples for TEM examination; a thin gold layer was also deposited onto the surface of the garnet sample to improve the imaging contrast. The procedures and the process parameters used to prepare the samples for TEM experiments together with the information on the imaging studies are described in [12].

\section{Magnetic Circular Dichroism (MCD) Studies of Ultrathin Iron Garnet Films}

4.1. Measurements of MCD Spectra Conducted at Room Temperature. In this section, the results of an experimental

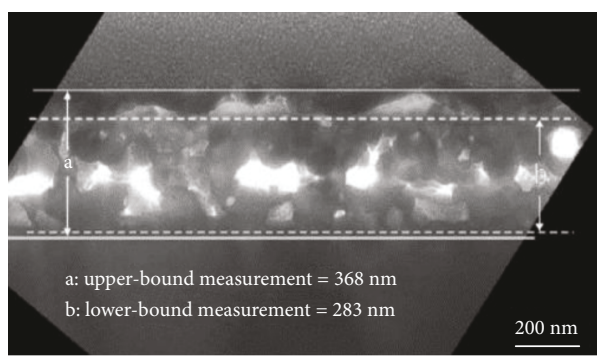

Figure 4: Transmission electron microscopy image of a crystallized garnet layer of nominal composition $\mathrm{Bi}_{2} \mathrm{Dy}_{1} \mathrm{Fe}_{4} \mathrm{Ga}_{1} \mathrm{O}_{12}$ studied and reported in [12].

study of the spectral dependencies of magnetic circular dichroism (MCD) in the wavelength range between $300 \mathrm{~nm}$ and $600 \mathrm{~nm}$ are reported, conducted with $\mathrm{Bi}_{2} \mathrm{Dy}_{1} \mathrm{Fe}_{4} \mathrm{Ga}_{1} \mathrm{O}_{12}$ iron garnet films of thicknesses $0.6 \mathrm{~nm}, 1.7 \mathrm{~nm}, 3.7 \mathrm{~nm}$, $10.3 \mathrm{~nm}$, and $100 \mathrm{~nm}$ at room temperature. $\mathrm{MCD}$ is a magneto-optic phenomenon manifesting as the difference in the optical absorption coefficients between the left hand and the right hand circularly polarized eigenmode constituents of a linearly polarized light wave.

The results obtained showed that the real morphological structure of the films was represented by the isolated or sometimes ingrown (merged) nanocrystallites forming flat-edged surface bumps of maximum heights not exceeding two or three nominal film thicknesses. The mean diameter of these surface roughness bumps measured at midheight was 


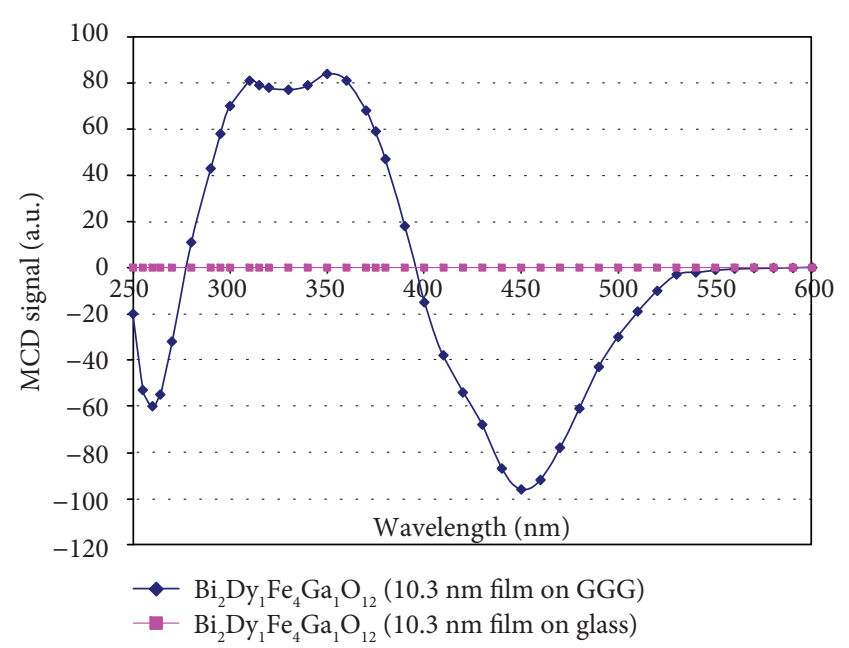

FIGURE 5: Spectral dependency of the MCD signal (blue diamond) measured in a $10.3 \mathrm{~nm}$-thick iron garnet film of nominal composition $\mathrm{Bi}_{2} \mathrm{Dy}_{1} \mathrm{Fe}_{4} \mathrm{Ga}_{1} \mathrm{O}_{12}$ grown on a gadolinium gallium garnet (GGG) substrate. Films of the same thickness and composition grown on glass substrates did not show (pink square) any magneto-optic activity. The dichroghraph sensitivity scale used was $5 \times 10^{-6}$.

near $100 \mathrm{~nm}$, for the $3.7 \mathrm{~nm}$-thick sample. Measurements of MCD spectra were performed using a dichrograph instrument (MARK-III by Jobin-Ivon). All room-temperature measurements were made in the wavelength interval between $300 \mathrm{~nm}$ and $800 \mathrm{~nm}$. For films of thicknesses $10.3 \mathrm{~nm}$ and $50 \mathrm{~nm}$ measured at room temperature, MCD spectral dependencies typical of bismuth-substituted iron garnets of this composition type were seen. The spectral dependency of MCD signal obtained from a $10.3 \mathrm{~nm}$-thick sample is shown in Figure 5.

The negative MCD signal peak at $450 \mathrm{~nm}$ and the positive peak at $360 \mathrm{~nm}$ are related to the presence of a large concentration of bismuth ions in the structure of ferrite garnet, which affects dramatically the MO properties of bismuthsubstituted yttrium iron garnet material in the spectral interval between $330 \mathrm{~nm}$ and $2000 \mathrm{~nm}$. It is important to note that the signs of both the Faraday effect and also MCD in the samples studied, across the UV and visible spectral ranges, were the opposite with respect to these measured typically in bismuth-substituted yttrium iron garnets. This can be attributed to the fact that, in bismuth-substituted yttrium iron garnets, the garnet's tetrahedral magnetic sublattice orients magnetically along the externally applied magnetic field, whereas in the samples studied (bismuth-substituted dysprosium gallium iron garnet), the magnetic moment of the octahedral sublattice orients itself along the external magnetic field. This is related to the strong dilution of the tetrahedral magnetic sublattice by nonmagnetic gallium ions and to the presence of a large number of dysprosium ions inside the dodecahedrical magnetic sublattice.

At first glance, the spectral dependencies of the Faraday effect and MCD measured over the range from $330 \mathrm{~nm}$ to $800 \mathrm{~nm}$ are attributed to the fact that the introduction of bismuth into the iron garnet structure leads to the appearance of a magneto-optical peculiarities between 330 and $500 \mathrm{~nm}$. More rigorous analysis has shown that new giant magneto-optical peculiarities near $90 \mathrm{~nm}$ in Bisubstituted iron garnets are related to at least four intensive absorption transitions with paramagnetic FR and MCD and to one transition with diamagnetic dispersion FR and MCD [13-20].

In reality, the situation is much more complex. Detailed analysis of the Faraday effect and MCD spectra measured at low temperatures together with the theoretical analysis of the MO properties in yttrium iron garnet leads us to conclude that the two peaks identified (at $450 \mathrm{~nm}$ and $360 \mathrm{~nm}$ ) are in fact related to several optical transitions of both the paramagnetic and the diamagnetic type. These are typically observed in yttrium iron garnets (the transition at $\lambda=430 \mathrm{~nm}$ of oscillator strength $f=2 \times 10^{-3}$, the transition at $\lambda=390 \mathrm{~nm}$ of oscillator strength $f=4 \times 10^{-3}$, and the transition at $\lambda=365 \mathrm{~nm}$ of oscillator strength $f=1 \times 10^{-2}$ ) [14-20].

The origins of these strong absorption bands may be related to double excitons [14], that is, the transitions where two $\mathrm{Fe}^{3+}$ ions within the same sublattice or different sublattices are simultaneously excited to the spin-quartet levels, for example,

$$
6 \mathrm{~A} 1 \mathrm{~g}(6 \mathrm{~S}) \rightarrow 4 \mathrm{~T} 1 \mathrm{~g}(4 \mathrm{G})+6 \mathrm{~A} 1 \mathrm{~g}(6 \mathrm{~S}) \rightarrow 4 \mathrm{~T} 1 \mathrm{~g}(4 \mathrm{G}) .
$$

Another model of the absorption mechanism for the spectral range below $\lambda=450 \mathrm{~nm}$ is based on the assumption that intense absorption bands are related to iron-iron charge-transfer transitions between the octahedral and tetrahedral pairs, for example,

$$
\begin{aligned}
& \left(\mathrm{Fe}^{3+}\right)_{\mathrm{T} 2}+\mathrm{hv} \rightarrow\left[\mathrm{Fe}^{2+}\right]_{\mathrm{T} 2 \mathrm{~g}}(\lambda=433 \mathrm{~nm}), \\
& {\left[\mathrm{Fe}^{3+}\right]_{\mathrm{Eg}}+\mathrm{hv} \rightarrow\left[\mathrm{Fe}^{2+}\right]_{\mathrm{E}}(\lambda=390 \mathrm{~nm}),} \\
& {\left[\mathrm{Fe}^{3+}\right]_{\mathrm{Eg}}+\mathrm{hv} \rightarrow\left(\mathrm{Fe}^{2+}\right)_{\mathrm{T} 2}(\lambda=344 \mathrm{~nm}),} \\
& \left(\mathrm{Fe}^{3+}\right)_{\mathrm{T} 2}+\mathrm{hv} \rightarrow\left[\mathrm{Fe}^{2+}\right]_{\mathrm{Eg}}(\lambda=303 \mathrm{~nm}) .
\end{aligned}
$$

The oscillator strengths of some of the abovementioned optical transitions grow by about two orders in magnitude, when bismuth ions are introduced into the structure of iron garnet, up to the substitution level of three formula units. It should be noted here that films of the same thickness and composition grown on glass substrates did not show any magneto-optic activity in the entire spectral region.

The observed negative sign of the MCD effect near $450 \mathrm{~nm}$ reveals that in this thin film garnet material, the octahedral magnetic sublattice was orienting itself in the direction of the magnetic field applied externally, that is, the film investigated had a so-called compensation point at above the room temperature. At the optimum measurement conditions, the dichrograph registers reliably a signal of magnitude 5 (a.u.). Realistically, 5 a.u. of signal strength corresponds to $5 \mathrm{~mm}$ of space on the data curve recorded at the maximum sensitivity settings. Adjusting for the sample thickness $10.3 \mathrm{~nm}$, we get $480 \cdot 10^{-6}$ (a.u.) divided by $10.3 \mathrm{~nm}$ or 48 (a.u.) $/(1 \mathrm{~nm})$ in arbitrary units per nanometer of sample 


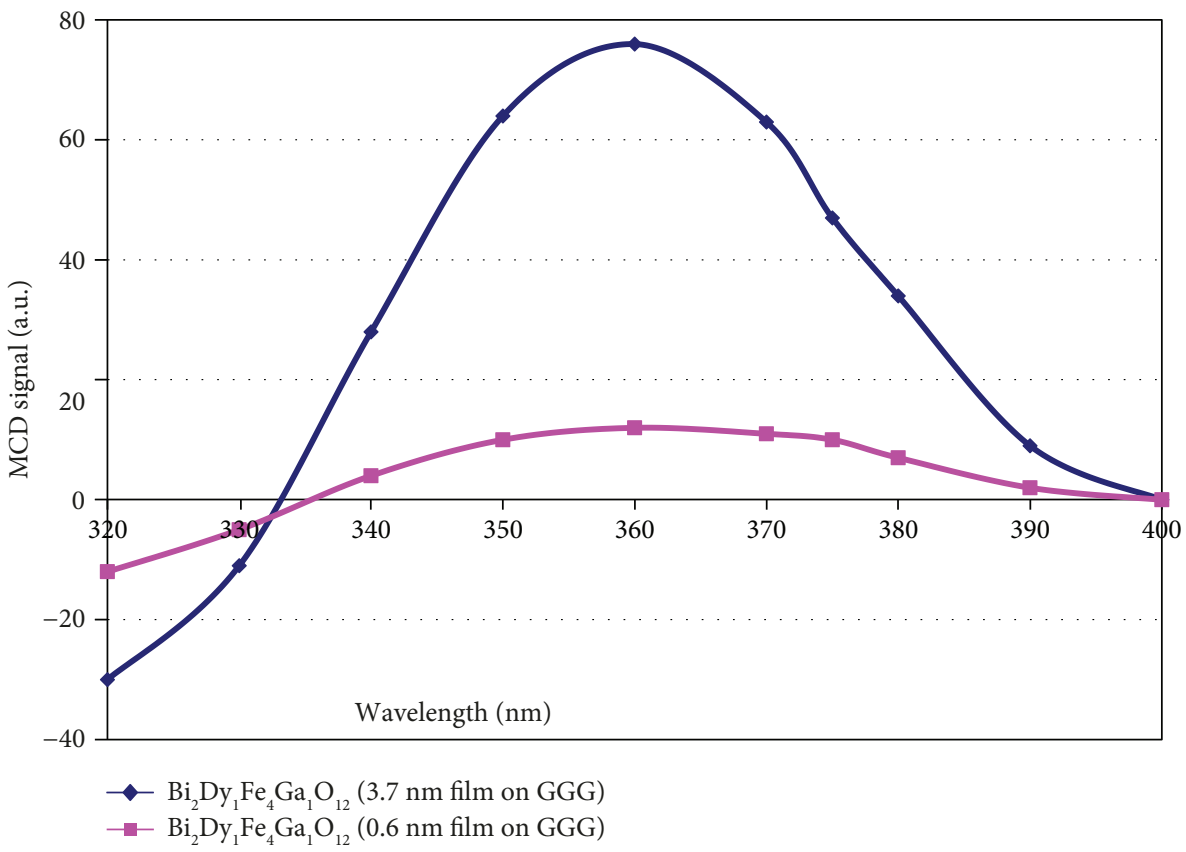

FIGURE 6: Room-temperature MCD spectra measured in films of thicknesses $0.6 \mathrm{~nm}$ (pink square) and $3.7 \mathrm{~nm}$ (blue diamond) deposited onto GGG substrates. Dichroghraph sensitivity scale used was $2 \times 10^{-6}$.

thickness. A series of prior publications have shown that transitional garnet layers of $4-5 \mathrm{~nm}$ thickness did not possess magneto-optic activity at room temperature. Accounting for this thickness correction, the strength of MCD signal per unit $(1 \mathrm{~nm})$ of sample thickness will be twice higher for a $10.3 \mathrm{~nm}$-thick sample. We can also conclude from the results obtained that, for the MO material under study, during the measurements of MCD at $450 \mathrm{~nm}$ wavelength, the dichrograph can register reliably the signal from film samples as thin as only $1 \AA$, if the film possesses magnetic ordering of iron ions. The only problem is the presence of magnetic ordering in bismuth-containing ferrite garnet films at the room temperature or at helium temperature.

The observed signs of MCD effect within different spectral regions point to the fact that in this thin film garnet material, the octahedral magnetic sublattice was orienting itself in the direction of the magnetic field applied externally. The measurements of the MCD spectra made at room temperature with film samples of thicknesses $0.6,1.7$, and $3.7 \mathrm{~nm}$ deposited onto GGG substrates did not exhibit the typical MCD spectra features characteristic of bismuth-substituted iron garnets. At the same time, near the signal-detection limits of dichrograph's sensitivity, it was possible to identify the presence of some very weak magneto-optic activity in the spectral interval between $300 \mathrm{~nm}$ and $400 \mathrm{~nm}$. These measured spectral dependencies are shown in Figure 6.

The maximum MCD signal value at $360 \mathrm{~nm}$ reached 24 a.u. for the $0.6 \mathrm{~nm}$-thick sample and 152 a.u. for the $3.7 \mathrm{~nm}$-thick sample, at the sensitivity scale of $1 \times 10^{-6}$. The observed MCD signals may be attributed to the presence of magnetite nanocrystallites, which form as a result of bismuth ion losses occurring during the deposition process and during the subsequent high-temperature annealing of ultrathin films.
4.2. Measurements of MCD Spectra Conducted at Low Temperatures. In order to obtain additional information on the properties of ultrathin ferrite garnet films and to study the structure of any transition layers existing near the substrate-film boundary, as well as the compositional changes of films occurring with increasing thickness, we performed low-temperature spectral MCD measurements between $300 \mathrm{~K}$ and $8 \mathrm{~K}$, for films of thicknesses $0.6,1.7$, and $3.7 \mathrm{~nm}$. Measurement results are shown in Figures 7 and 8 . The results of our present study reveal that even in films as thin as these, no complete loss of bismuth content occurs after annealing the layers at $650^{\circ} \mathrm{C}$.

The maximum MCD signal value measured in this sample at $440 \mathrm{~nm}$ reached 890 a.u. at the $1 \bullet 10^{-6}$ sensitivity scale. The presence of two MCD signal bands with extreme at $440 \mathrm{~nm}$ and $390 \mathrm{~nm}$ is characteristic of ferrite garnet films with high levels of gallium ion substitution within the iron ion sites of the tetrahedral sublattice of garnet. In this case, it can be expected that dilution of the tetrahedral lattice sites by gallium ions occurs, with these gallium ions supplied from the substrate composed of gadolinium gallium garnet. The spectral position of the first (long-wavelength) intense MCD signal peak near $440 \mathrm{~nm}$ is characteristic of bismuthsubstituted iron garnets of lattice parameter close to $a_{\mathrm{f}}=$ $12.383 \AA$. With increasing bismuth substitution in a garnet structure, a red-shifting effect occurs for this MCD signal band, which in the films studied in the present work is near $440 \mathrm{~nm}$. For iron garnets of composition $\mathrm{Bi}_{2.8} \mathrm{Y}_{0.2} \mathrm{Fe}_{5} \mathrm{O}_{12}$, the long-wave MCD peak is shifted towards $490 \mathrm{~nm}$ [21]. The spectral position of this MCD peak remains at $490 \mathrm{~nm}$ for all films of thickness between 15 and $160 \mathrm{~nm}$.

The measured MCD spectra of the $1.7 \mathrm{~nm}$-thick sample for different temperatures over the range $8 \mathrm{~K}$ to $200 \mathrm{~K}$ are 


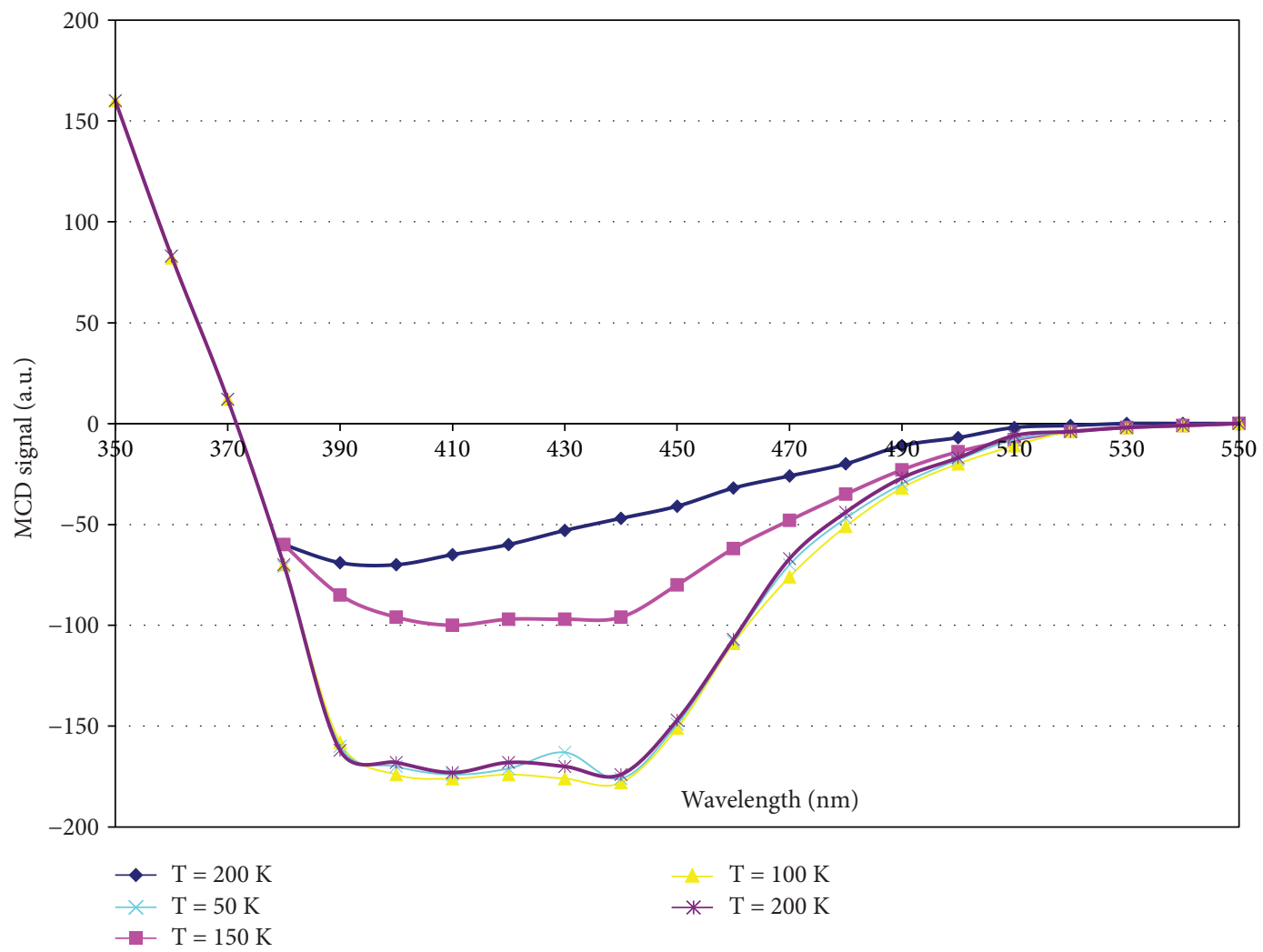

FIgure 7: Spectral MCD signal dependencies measured in a $3.7 \mathrm{~nm}$-thick sample of nominal composition $\mathrm{Bi}_{2} \mathrm{Dy}_{1} \mathrm{Fe}_{4} \mathrm{Ga}_{1} \mathrm{O}_{12}$ at different sample temperatures between $200 \mathrm{~K}$ and $8 \mathrm{~K}$. (1) $200 \mathrm{~K}$, (2) $150 \mathrm{~K}$, (3) $100 \mathrm{~K}$, (4) $50 \mathrm{~K}$, (5) $8 \mathrm{~K}$. Dichroghraph sensitivity scale was $5 \times 10^{-6}$.

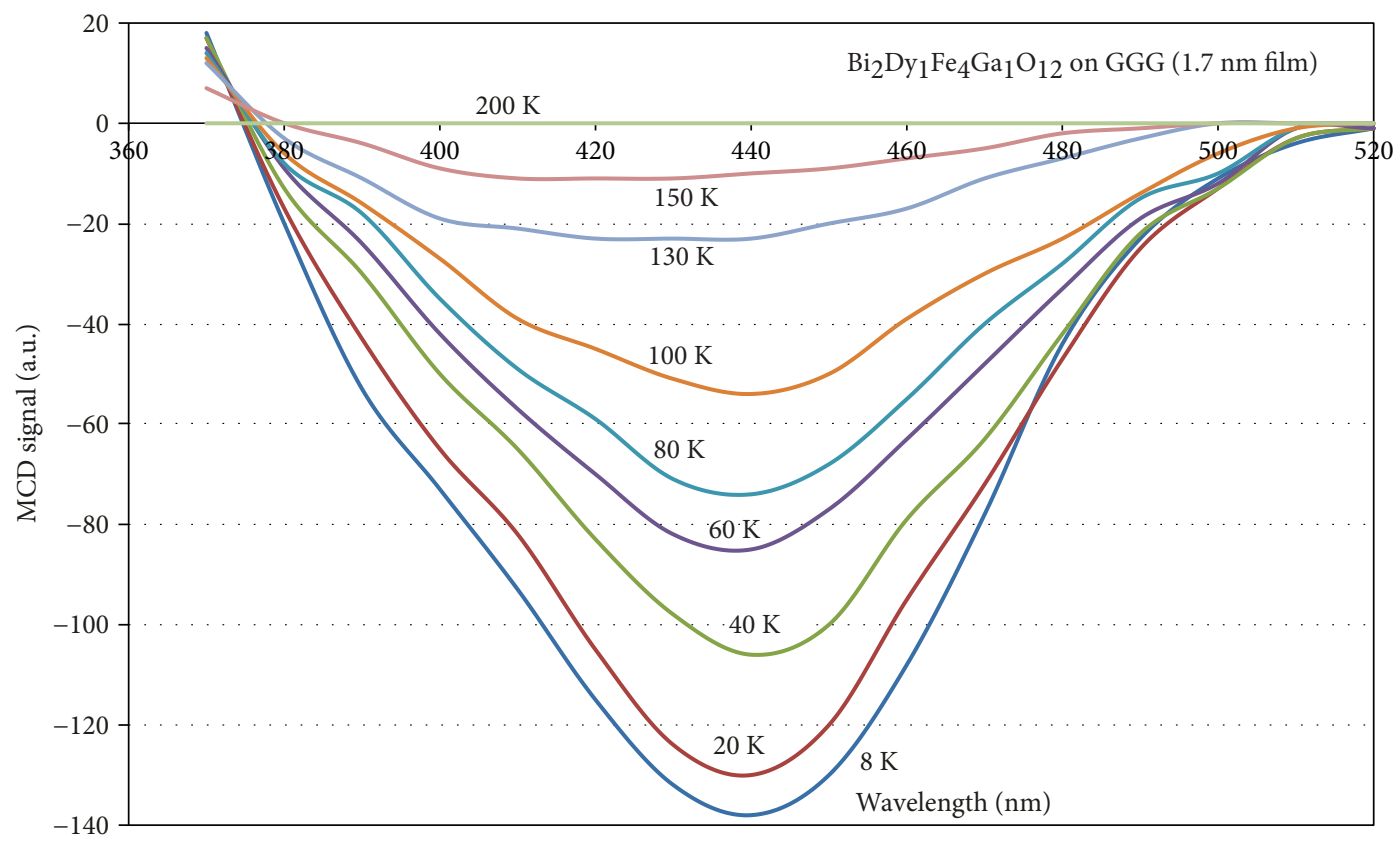

Figure 8: MCD spectral dependencies measured in a $1.7 \mathrm{~nm}$-thick sample of iron garnet film between $200 \mathrm{~K}$ and $8 \mathrm{~K}$ (the signal was also at zero level at $300 \mathrm{~K})$. The sensitivity of dichroghraph scale was $2 \times 10^{-6}$.

shown in Figure 8. The signal strength at the peak of the MCD band at $440 \mathrm{~nm}$ reached 278 a.u. at sensitivity scale $1 \times 10^{-6}$. For the $3.7 \mathrm{~nm}$-thick sample, the main difference in MCD spectra was the significant reduction in the MCD strength over the $400 \mathrm{~nm}$ signal band compared to the reduction in the $440 \mathrm{~nm}$ band. As was already noted, the 
negative sign of MCD signal in the spectral interval between $370 \mathrm{~nm}$ and $550 \mathrm{~nm}$ and the observed shapes of spectral dependencies at temperatures between $150 \mathrm{~K}$ and $8 \mathrm{~K}$ (MCD peak locations near 445 and $400 \mathrm{~nm}$ ) are characteristic of bismuth-substituted iron garnets in which the iron sites within the tetrahedral sublattice are diluted heavily with $\mathrm{Ga}^{3+}$ ions. The fact that in the samples studied the MCD signal was negative between $375 \mathrm{~nm}$ and $550 \mathrm{~nm}$ confirms that the magnetic moment of the octahedral sublattice of garnet is oriented along the direction of the external magnetic field.

At the same time, a different explanation is required for the spectral MCD dependency observed at $200 \mathrm{~K}$. The broad peak near $400 \mathrm{~nm}$ could be related to magnetite $\left(\mathrm{Fe}_{3} \mathrm{O}_{4}\right)$ nanocrystallites [11]. It is important to note that the shape of the MCD spectra observed at $150 \mathrm{~K}$ and at lower temperatures is characteristic of bismuth-substituted iron garnets. The location of the first MCD peak near $440 \mathrm{~nm}$ also points to the fact that the lattice parameter within the nanocrystallites of the films studied was near $12.383 \AA$. The available data allows the estimation of the lattice parameter within the quasi-2D nanocrystallites present within this $3.7 \mathrm{~nm}$-thick film. Proposing that the blocked state temperature $T_{\mathrm{B}}=215 \mathrm{~K}$ is close to the Neel temperature, we can expect based on the literature data that the real composition of ferrite garnet nanocrystallites differs significantly from the nominal composition $\mathrm{Bi}_{2} \mathrm{Dy}_{1} \mathrm{Fe}_{4}$ $\mathrm{Ga}_{1} \mathrm{O}_{12}$. Neel temperature near $215 \mathrm{~K}$ in gallium-diluted iron garnets corresponds to the substitution level of the iron ions by the gallium ions close to 3 formula units [22].

At a nominal thickness of $3.7 \mathrm{~nm}$ in this iron garnet film, considering also the presence of an intermediate "dead layer" of a few nanometer thickness near the GGG substrate interface, the hypothesized high substitution of the iron ions by gallium within tetrahedral lattice sites appears quite likely. This can be explained as follows: during the initial stages of garnet film deposition, amorphization of substrate occurs during $\mathrm{Ar}^{+}$ion bombardment, to depths between 1 and $2 \mathrm{~nm}$. During the annealing process, as a result of accelerated diffusion within this region, there occurs some compositional equalization of the film's contents within the amorphization region, and $\mathrm{Ga}^{3+}$ ion content reaches 2.5 formula units within this sublayer. This model is supported by the results of the MO property studies in ultrathin ferrite garnet films of nominal composition $\mathrm{Bi}_{2.8} \mathrm{Y}_{0.2} \mathrm{Fe}_{5} \mathrm{O}_{12}$ and by the fine structure in transitional layers between the substrate and film which is observed in these films [21].

By varying the bismuth and dysprosium contents, based on the available data, we can estimate the actual composition of the film's material. For the film of composition $\mathrm{Bi}_{0.4} \mathrm{Dy}_{2.6} \mathrm{Fe}_{2} \mathrm{Ga}_{3} \mathrm{O}_{12}$, the calculated lattice parameter value is

$$
\begin{aligned}
a_{\mathrm{f}}(\AA)= & 12,376(\AA)+0.4 * 0.0828(\AA)+2.6 * 0.0097(\AA) \\
& -3 * 0.0170(\AA)=12.383(\AA) .
\end{aligned}
$$

Here, $12.376 \AA$ is the lattice parameter of an iron garnet material of composition $\mathrm{Y}_{3} \mathrm{Fe}_{5} \mathrm{O}_{12}, 0.4 * 0.0828(\AA)$ is the change in the lattice parameter occurring due to introduction of a 0.4 formula unit of the $\mathrm{Bi}^{3+}$ ion substitution into garnet structure, $2.6 * 0.0097(\AA)$ is the corresponding lattice parameter change due to introducing 2.6 formula units of $\mathrm{Dy}^{3+}$ ion, and $3 * 0.0170(\AA)$ corresponds to the effect of $\mathrm{Ga}^{3+}$ ion dilution at 3 formula units. The coefficients used in the above calculation are taken from [22]. Here, it is important to note that the spectral location of the longwavelength peak in MCD spectra of bismuth-substituted ferrite garnets containing from 0.1 to 1.0 formula units of bismuth substitution is observed to be near $440 \mathrm{~nm}$, provided that the film's lattice parameter coincides with the substrate's lattice parameter of GGG, which equals to $a_{\mathrm{s}}=12.383 \AA$.

Another unusual result follows from the practically unchanging values of MCD signal when the sample temperature was varied between $100 \mathrm{~K}$ and $8 \mathrm{~K}$. Based on the analysis of the data shown in Figure 1(b), we can propose that Neel temperature of nanocrystalline ferrite garnet film of thickness $3.7 \mathrm{~nm}$ is near $215 \mathrm{~K}$, if extrapolating the horizontal section of the temperature dependency graph of MCD between $100 \mathrm{~K}$ and $8 \mathrm{~K}$ using a standard temperature dependency of the specific Faraday effect, as obtained from bulk garnet samples. We can also expect that, accounting for all of the above factors, the actual composition of nanocrystallites present inside the film of $3.7 \mathrm{~nm}$ thickness, also accounting for our estimated temperature of magnetic ordering and the location of the first MCD peak of bismuthsubstituted iron garnet near $440 \mathrm{~nm}$, has the following chemistry- $\mathrm{Bi}_{1} \mathrm{Dy}_{2} \mathrm{Fe}_{2.5} \mathrm{Ga}_{2.5} \mathrm{O}_{12}$. From the coincident curve shapes in MCD curves measured at 100,50 , and $8 \mathrm{~K}$, it follows that the fraction of the film's volume which contributes to the MCD signal at $100 \mathrm{~K}$ and below has a constant chemical composition, and its Neel temperature is near $150 \mathrm{~K}$.

4.3. Temperature Dependencies of MCD Signals at $440 \mathrm{~nm}$. The most interesting result is found when analyzing the temperature dependency of the MCD signal strength near the region of $440 \mathrm{~nm}$ peak for film samples of thicknesses $3.7 \mathrm{~nm}$ and $1.7 \mathrm{~nm}$. Figures 9 and 10 show the temperature dependency of MCD signal strength at $440 \mathrm{~nm}$ for $3.7 \mathrm{~nm}$ and $1.7 \mathrm{~nm}$-thick film samples.

For the analysis of measured data, it makes sense to split the curve shown in Figure 5 into two temperature intervals. The first interval is between $8 \mathrm{~K}$ and $100 \mathrm{~K}$. Within this temperature region, the MCD signal strength at $440 \mathrm{~nm}$ is practically unchanged (in reality, it is reduced by $1.5 \%$ with the temperature decreasing from $100 \mathrm{~K}$ to $8 \mathrm{~K})$. A reduction in MCD signal within this exact interval has been observed previously (but notably to a much greater extent in the MCD signal strength reduction) in epitaxial-quality films of bismuth-substituted iron garnets grown by LPE [23]. The explanation for this effect, based on the molecular field theory, is given in 23 , where a good agreement was reported between the theory predictions and experimental data.

At higher temperatures, in between $100 \mathrm{~K}$ and $215 \mathrm{~K}$, linear reduction in the strength of MCD signal is observed. 


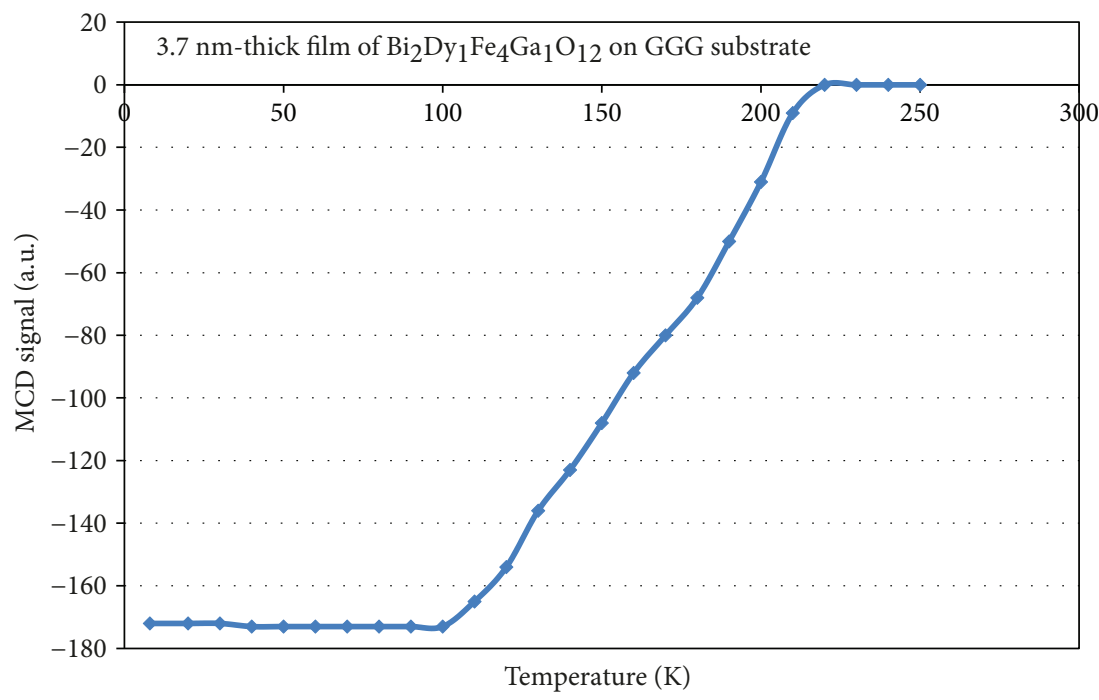

FIGURE 9: Temperature dependency of MCD signal strength near $440 \mathrm{~nm}$ peak measured in $3.7 \mathrm{~nm}$-thick garnet sample. Dichroghraph sensitivity scale was $5 \times 10^{-6}$.

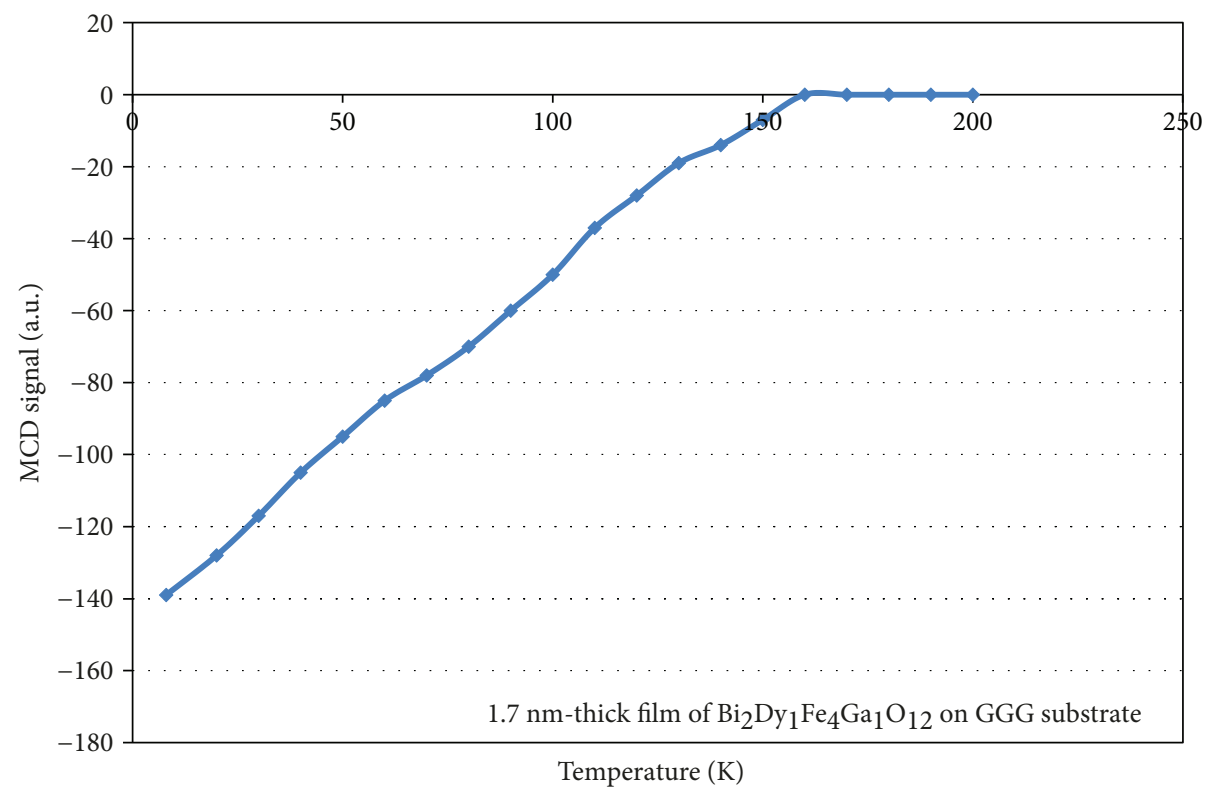

Figure 10: Temperature dependency of the MCD signal near $440 \mathrm{~nm}$ peak for $1.7 \mathrm{~nm}$-thick film. Dichroghraph sensitivity scale was $1 \times 10^{-6}$.

This region of temperature dependency points to a superparamagnetic behaviour of the object of study, with the blocking temperature being near $215 \mathrm{~K}$. The appearance of a superparamagnetic region can be explained as follows: for a film of nominal thickness $3.7 \mathrm{~nm}$, one can expect the appearance of quasi-2D nanocrystallite islands during the annealing crystallization process. These islands will be similar in their appearance to very flat bumps on the substrate surface. The studies of surface morphology made with thin garnet films of nominal composition $\mathrm{Bi}_{2.8} \mathrm{Y}_{0.2} \mathrm{Fe}_{5} \mathrm{O}_{12}$ and thickness between $4 \mathrm{~nm}$ and $100 \mathrm{~nm}$ using scanning probe microscopy revealed that for a film thickness around $5 \mathrm{~nm}$, flat bumps appear on the film surface, the heights of which exceed the nominal film thickness by several times [21].
Based on the magnitude of the MO effects observed, one can conclude that for a nominal film thickness greater than $12 \mathrm{~nm}$, the film had a constant composition $\mathrm{Bi}_{2.8} \mathrm{Y}_{0.2} \mathrm{Fe}_{5} \mathrm{O}_{12}$ throughout the thickness interval from about $12 \mathrm{~nm}$ up to its top-surface boundary. In [21], the maximum film thickness studied was $100 \mathrm{~nm}$ and the minimum $2.9 \mathrm{~nm}$. Besides, no anomalies were observed with decreasing temperature, down to the material's Neel temperature. Therefore, it is possible to assume that the volume regions in between any larger-size nanocrystallites were filled with smaller ones. The mutual ingrowth between nanocrystallites enabled significant exchange coupling between all structural elements within the films. For the $3.7 \mathrm{~nm}$-thick film sample studied in the present work, the nanocrystallite edges overlapped, 
and for the thickness of the magnetic layer near the regions of overlap between neighboring quasi-2D nanocrystallites being around several nanometers, at low temperatures, all nanocrystallites together behaved as quasibulk material. At high temperatures, the system of nanocrystallites of larger size typically exhibits a superparamagnetic state.

The measured temperature dependency is essentially represented by a straight line, and through data extrapolation, the calculated blocking temperature is around $160 \mathrm{~K}$. We believe that for this $1.7 \mathrm{~nm}$-thick film sample, the results obtained can be interpreted as follows: a $1.7 \mathrm{~nm}$-thick (ultrathin) sample comprises an ensemble of quasi-2D nanocrystallites (very flat surface bumps of 3-5 $\mathrm{nm}$ height and width at base between 10 and $100 \mathrm{~nm}$ ), between the boundaries of which the exchange interaction is absent. As a result of this, the sample demonstrated superparamagnetic behaviour over the entire temperature interval. Since the thermal expansion coefficients of bismuth-substituted iron garnets exceed those of GGG substrate by about $10 \%$ and since the annealing processes are run at $650^{\circ} \mathrm{C}$, at room temperature the nanocrystallites typically experience the state of an in-plane tensile stretching, hence possessing uniaxial magnetic anisotropy with a positive constant of uniaxial magnetic anisotropy. Because of the low-saturated magnetization in iron garnets of this composition type, the uniaxial magnetic anisotropy condition $K_{\mathrm{u}}>2 \pi M_{s}^{2}$ will be satisfied.

\section{Conclusions}

Studies of the magneto-optic properties of ultrathin bismuthsubstituted iron garnet films have been performed for the first time for films of nominal thicknesses 0.6, 1.7, and $3.7 \mathrm{~nm}$. The film samples have been prepared on gadolinium gallium garnet substrates by RF magnetron sputtering followed by annealing crystallization at $650^{\circ} \mathrm{C}$. At room temperature, the spectral dependencies of magnetic circular dichroism have been measured in the spectral interval between $250 \mathrm{~nm}$ and $850 \mathrm{~nm}$. At cryogenic temperatures down to $8 \mathrm{~K}, \mathrm{MCD}$ dependencies have been measured between $300 \mathrm{~nm}$ and $850 \mathrm{~nm}$. At room temperature in samples of thickness exceeding $5 \mathrm{~nm}$, the MCD spectra typical of bismuth-substituted iron garnets have been measured. For ultrathin films of thicknesses $0.6,1.7$, and $3.7 \mathrm{~nm}$, no magneto-optic effects linked to the presence of bismuthsubstituted iron garnet nanocrystallites have been observed at room temperature. Experimental results have shown that, at temperatures below $160 \mathrm{~K}$, for a film of $1.7 \mathrm{~nm}$ thickness, the observed MCD spectrum is mainly due to the presence of $\mathrm{Bi}_{1} \mathrm{Dy}_{2} \mathrm{Fe}_{2.5} \mathrm{Ga}_{2.5} \mathrm{O}_{12}$ nanocrystallites, whereas over the temperature range between $100 \mathrm{~K}$ and $8 \mathrm{~K}$, the magnetooptic activity typical of $\mathrm{Bi}_{1} \mathrm{Dy}_{2} \mathrm{Fe}_{2.5} \mathrm{Ga}_{2.5} \mathrm{O}_{12}$ nanocrystallites is dominant. The gallium ion content has been estimated, based on the Neel temperature estimation. The bismuth substitution levels have been estimated based on the magnitudes of the specific MCD signal strength obtained from the measurements. Here, it is important to note that the theoretically calculated lattice parameter for a film of a given composition was $a_{\mathrm{f}}=12.390 \AA$, which is very close to the GGG substrate lattice parameter $(12.383 \AA)$.

\section{Conflicts of Interest}

The authors declare no conflict of interest.

\section{Authors' Contributions}

The Australian team (M. Nur-E-Alam, M. Vasiliev, and K. Alameh) fabricated the ultrathin film batches and provided their optical and also the X-ray diffractometry characterization; the Russian teams have provided a comprehensive scanning probe microscopy analyses and low-temperature characterization of the magnetic and MO properties. All authors construed to the analysis of the data and the write-up of the final manuscript.

\section{Acknowledgments}

The samples of ferrite garnet films were fabricated by Edith Cowan University (Perth, Australia); the studies of their optical, magnetic, and magneto-optical properties (including low-temperature measurements) have been conducted by the V.A. Kotelnikov Institute of Radio Technology and Electronics of the Russian Academy of Sciences and at the Moscow Institute of Physics and Technology (MIPT), supported by grant from the Russian Science Foundation (Project code 14-22-00279). AFM measurements were conducted at MIPT (Moscow), supported by Russian Foundation for Basic Research grants 16-07-00734 and 16-07-00735.

\section{References}

[1] Y. Kajiwara, K. Harii, S. Takahashi et al., "Transmission of electrical signals by spin-wave interconversion in a magnetic insulator," Nature, vol. 464, no. 7286, pp. 262-266, 2010.

[2] H. Kurebayashi, O. Dzyapko, V. E. Demidov, D. Fang, A. J. Ferguson, and S. O. Demokritov, "Controlled enhancement of spin-current emission by three-magnon splitting," Nature Materials, vol. 10, no. 9, pp. 660-664, 2011.

[3] H. Wang, Y. Li, L. Sun et al., "Electrospun novel bifunctional magnetic-photoluminescent nanofibers based on $\mathrm{Fe}_{2} \mathrm{O}_{3}$ nanoparticles and europium complex," Journal of Colloid and Interface Science, vol. 350, no. 2, pp. 396-401, 2010.

[4] A. Brataas, A. D. Kent, and H. Ohno, "Current-induced torques in magnetic materials," Nature Materials, vol. 11, no. 5, pp. 372-381, 2012.

[5] H. Dötsch, N. Bahlmann, O. Zhuromskyy et al., "Applications of magneto-optical waveguides in integrated optics: review," Journal of the Optical Society of America B, vol. 22, no. 1, pp. 240-253, 2005.

[6] S. A. Manuilov, R. Fors, S. I. Khartsev, and A. M. Grishin, "Submicron $\mathrm{Y}_{3} \mathrm{Fe}_{5} \mathrm{O}_{12}$ film magnetostatic wave band pass filters," Journal of Applied Physics, vol. 105, no. 3, article 033917, 2009.

[7] M. Nur-E-Alam, M. Vasiliev, K. Alameh, V. Kotov, V. Demidov, and D. Balabanov, "YIG: $\mathrm{Bi}_{2} \mathrm{O}_{3}$ nanocomposite thin films for magnetooptic and microwave applications," Journal of Nanomaterials, vol. 2015, Article ID 182691, 6 pages, 2015.

[8] S. Geller, H. J. Williams, G. P. Espinosa, R. C. Sherwood, and M. A. Gilleo, "Reduction of the preparation temperature of 
polycrystalline garnets by bismuth substitution," Applied Physics Letters, vol. 3, no. 2, pp. 21-22, 1963.

[9] Y. Sun, Y. Y. Song, H. Chang et al., "Growth and ferromagnetic resonance properties of nanometer-thick yttrium iron garnet films," Applied Physics Letters, vol. 101, no. 15, article 152405, 2012.

[10] V. A. Kotov, D. E. Balabanov, S. M. Grigorovich, V. I. Kozlov, and V. K. Nevolin, "Magnetic and magnetooptical properties of the transition layer in epitaxial bismuth-gallium iron garnet structures," Soviet Physics: Technical Physics, vol. 31, pp. 544-548, 1986, [J. Techn. Phys. 56 (5), 897-903 (1986) (in Russian)].

[11] S. Kale, S. M. Bhagat, S. E. Lofland et al., "Film thickness and temperature dependence of the magnetic properties of pulsed-laser-deposited $\mathrm{Fe}_{3} \mathrm{O}_{4}$ films on different substrates," Physical Review B, vol. 64, no. 20, 2001.

[12] P. C. Wo, P. R. Munroe, M. Vasiliev, Z. H. Xie, K. Alameh, and V. Kotov, "A novel technique for microstructure characterization of garnet films," Optical Materials, vol. 32, no. 2, pp. 315-322, 2009.

[13] J. Suits, "Faraday and Kerr effects in magnetic compounds," IEEE Transactions on Magnetics, vol. 8, no. 1, pp. 95-105, 1972.

[14] G. B. Scott, D. E. Lacklison, and J. L. Page, "Absorption spectra of $\mathrm{Y}_{3} \mathrm{Fe}_{5} \mathrm{O}_{12}$ (YIG) and $\mathrm{Y}_{3} \mathrm{Ga}_{5} \mathrm{O}_{12}: \mathrm{Fe}^{3+}$," Physical Review $B$, vol. 10, no. 3, pp. 971-986, 1974.

[15] K. W. Blazey, "Wavelength-modulated spectra of some $\mathrm{Fe}^{3+}$ oxides," Journal of Applied Physics, vol. 45, no. 5, pp. 2273-2280, 1974.

[16] S. Wittekoek, T. J. A. Popma, J. M. Robertson, and P. F. Bongers, "Magneto-optic spectra and the dielectric tensor elements of bismuth-substituted iron garnets at photon energies between 2.2-5.2 eV," Physical Review B, vol. 12, no. 7, pp. 2777-2788, 1975.

[17] G. B. Scott and J. L. Page, "Pb valence in iron garnets," Journal of Applied Physics, vol. 48, no. 3, pp. 1342-1349, 1977.

[18] G. B. Scott and J. L. Page, "The absorption spectra of $\mathrm{Y}_{3} \mathrm{Fe}_{5} \mathrm{O}_{12}$ and $\mathrm{Y}_{3} \mathrm{Ga}_{5} \mathrm{O}_{12}: \mathrm{Fe}^{3+}$ to $5.5 \mathrm{eV}$," Physica Status Solidi, vol. 79, no. 1, pp. 203-213, 1977.

[19] A. V. Zenkov and A. S. Moskvin, "Bismuth-induced increase of the magneto-optical effects in iron garnets: a theoretical analysis," Journal of Physics: Condensed Matter, vol. 14, pp. 6957-6968, 2002.

[20] A. K. Zvezdin and V. A. Kotov, Modern Magnetooptics and Magnetooptical Materials, Institute of Physics Publishing, Bristol, UK, 1997.

[21] A. N. Shaposhnikov, A. R. Prokopov, A. V. Karavainikov et al., "Modification of Bi: YIG film properties by substrate surface ion pre-treatment," Materials Research Bulletin, vol. 55, pp. 19-25, 2014.

[22] A. H. Eschenfelder, Magnetic Bubble Technology, SpringerVerlag, New York, NY, USA, 1981.

[23] P. Hansen and J. P. Krumme, "Magnetic and magneto-optical properties of garnet films," Thin Solid Films, vol. 114, no. 1-2, pp. 69-107, 1984. 


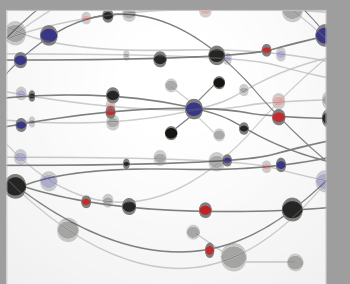

The Scientific World Journal
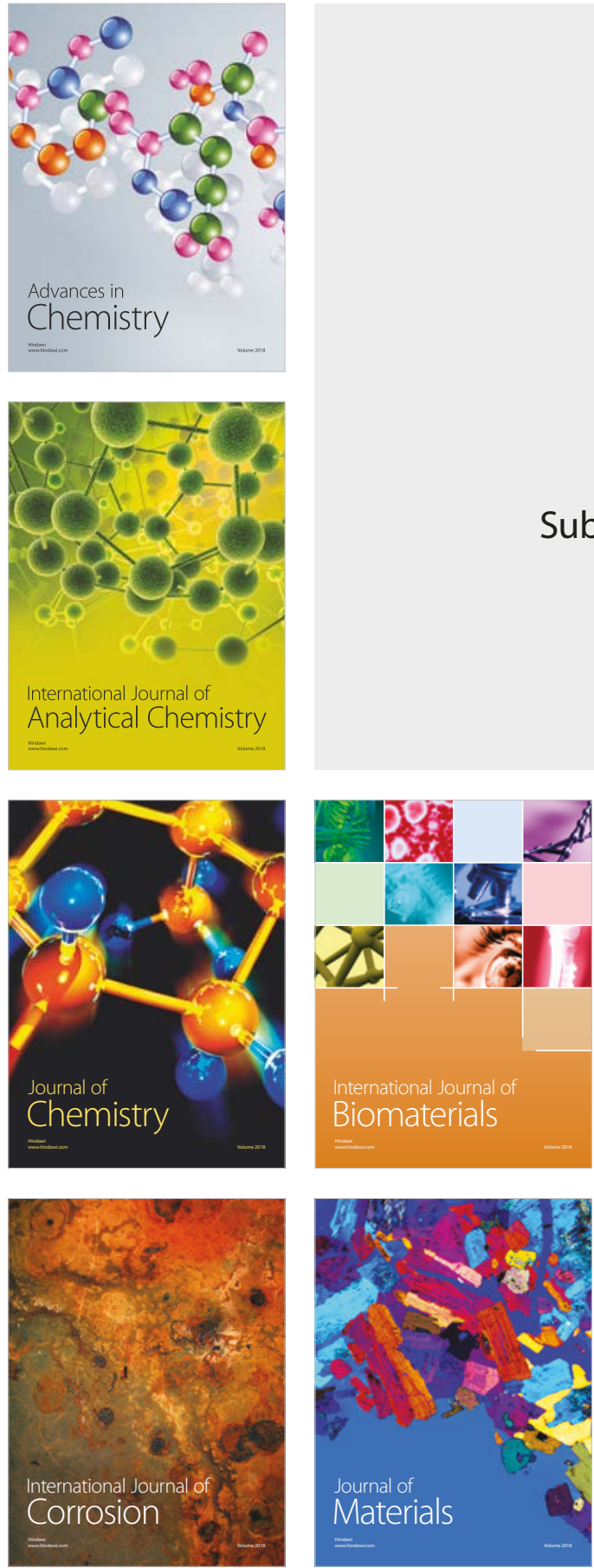

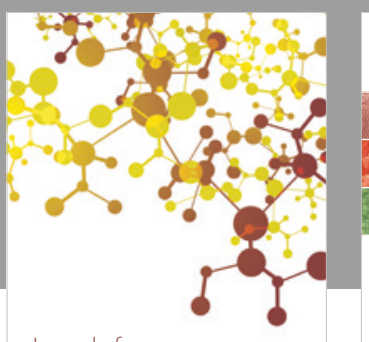

Journal of

Applied Chemistry
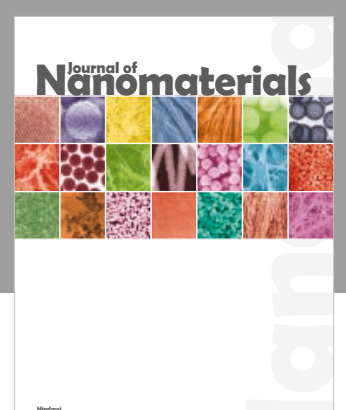

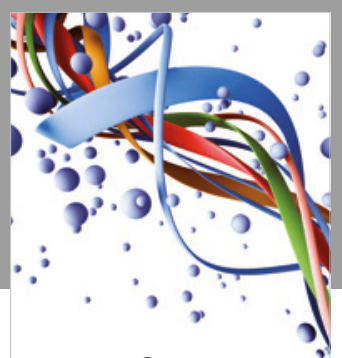

Scientifica

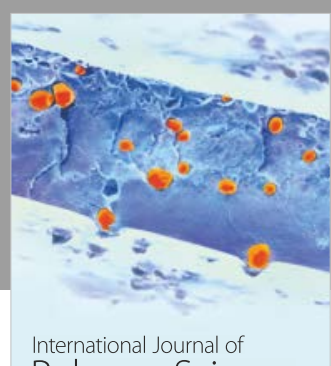

Polymer Science

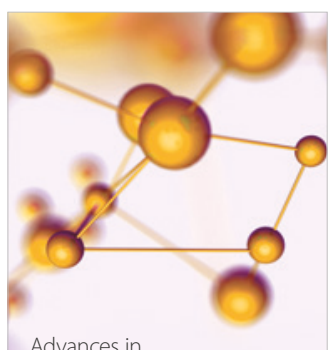

Physical Chemistry
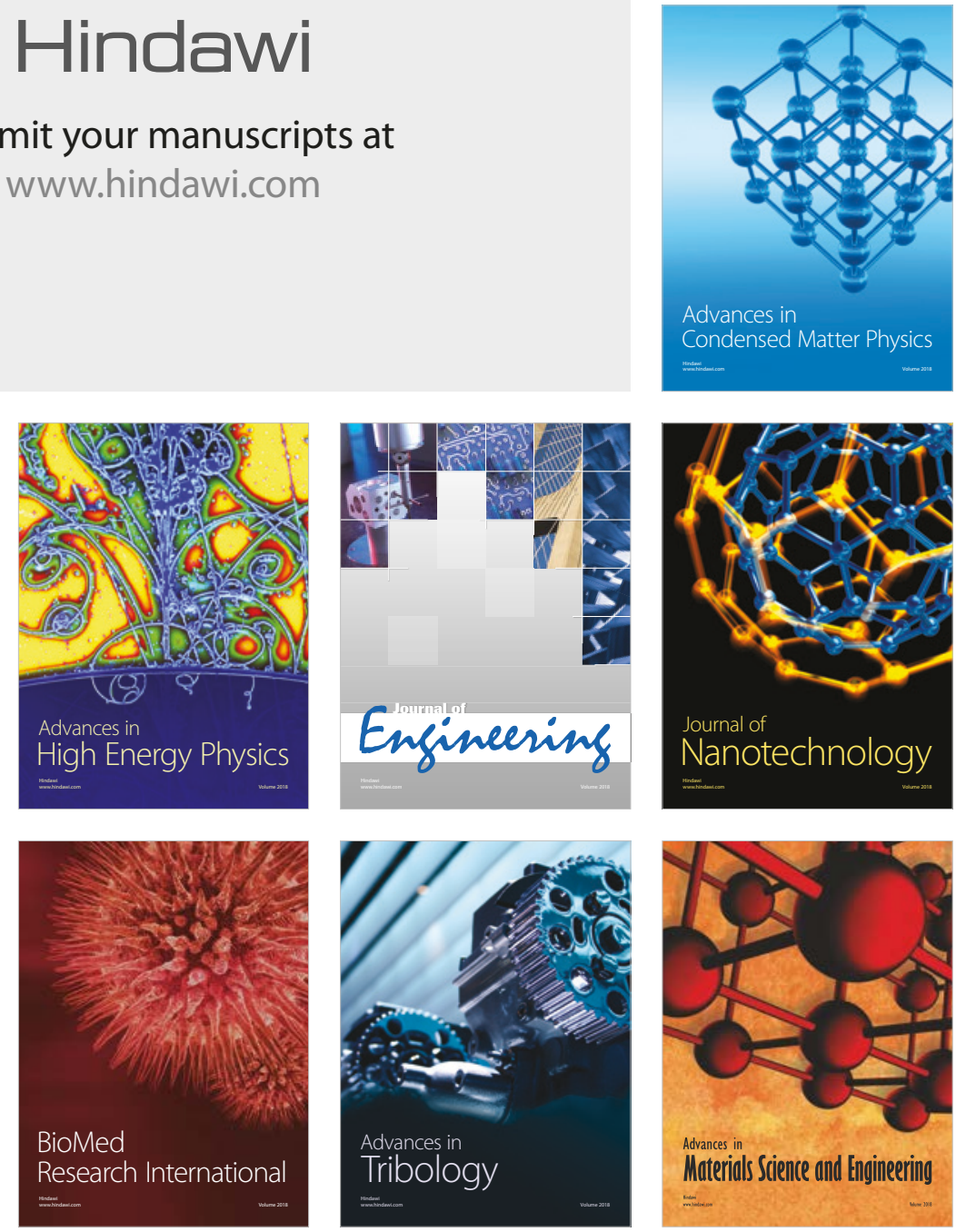